\title{
Mapping the real micro/nanostructures for the prediction of elastic moduli of polypropylene/clay nanocomposites
}

\author{
Yu Dong ${ }^{a, *}$, Debes Bhattacharyya ${ }^{\mathrm{b}}$ \\ ${ }^{a}$ Department of Mechanical Engineering, Curtin University of Technology, Perth, \\ WA 6845, Australia \\ ${ }^{\mathrm{b}}$ Centre for Advanced Composite Materials, The University of Auckland, Private Bag 92019 \\ Auckland, New Zealand
}

\begin{abstract}
An understanding of the overall nanocomposite behaviour is developed through the combination of real data from micro/nanostructures and the fundamental material characteristics of the constitutive phases. Captured morphological images, using either scanning electron microscopy (SEM) or transmission electron microscopy (TEM), are utilised to generate the geometric information regarding mapping the micro/nanostructures. The material properties, on the other hand, are obtained from conducted tests and previous literature. The numerical results predicting the elastic moduli of polypropylene (PP)/clay nanocomposites are compared with the experimental data and available composites theoretical models. Very good agreement has been shown, establishing the viability of this kind of morphology-based numerical approach.
\end{abstract}

Keywords: Polymer/clay nanocomposites; Mechanical properties; Finite element analysis

\section{Introduction}

The success of using layered silicates as nanofillers in polymer nanocomposites (e.g. polyamide/clay nanocomposites) has greatly motivated researchers and engineers due to their capability to accomplish the tremendous property enhancements such as high stiffness, light weight and good heat resistance even at low clay contents $(\leq 5 \mathrm{wt} \%)$. Furthermore, the recent focus has

\footnotetext{
* Corresponding author. Tel.: +61 8 92669055; fax: +61 892662681.

E-mail address: Y.Dong@curtin.edu.au (Y. Dong).
} 
been extended to low cost polyolefin-based nanocomposites like using polypropylene (PP) as the polymer matrix. PP, as a commonly used commodity polymer, has a variety of material merits including low density, high thermal stability, excellent processibility as well as wide usages in automotive and packaging industries. Nevertheless, its low modulus relative to engineering polymers (e.g. nylon 6) might limit the material selection to meet the requirements of end users. This disadvantage can be potentially alleviated by the additional good clay dispersion. PP/clay nanocomposites, prepared by either conventional intensive shear mixing or twin screw extrusion, have been successfully produced with partially intercalated/exfoliated structures [1-5]. The major problem to address originates from very low interactions between the non-polar hydrophobic PP and hydrophilic clay to hinder the early stage of effective intercalation. The direct way to increase the compatibility between the PP matrix and clay lies in blending PP with compatibilisers such as maleic anhydride grafted PP (MAPP) oligomer to enlarge the interlayer spacing and facilitate the penetration of clay platelets. Although the complete clay exfoliation as the most favourable morphology of PP/clay nanocomposites has not been experimentally achieved till now, the enhancements of stiffness and strength at a low clay content are still very attractive from the industrial point of view.

So far, extensive processing, experimental testing and material characterisation of PP/clay nanocomposites have been substantially conducted [1-7]. However, an effective multi-scaled numerical approach to understand the fundamental deformation mechanisms for mechanical property enhancement and to predict the overall material behaviour of such nanocomposites from the complex constituents has not been fully developed. In general, the elastic moduli of nanocomposites have been predicted using three widely accepted approaches including composites theoretical models, finite element analysis (FEA) and molecular dynamic (MD) simulation. 
Composites theoretical models such as Halpin-Tsai and Mori-Tanaka models [8, 9] are very simple and rough closed-form analytical solutions, originally developed to predict the material properties of short-fibre composites. Certain efforts have been made with some success to use those models for estimating the elastic moduli [10-13], thermo-mechanical properties [10] and the reinforcement efficiency of polymer/clay nanocomposites [13]. As far as the numerical simulation is concerned, MD simulation considers far more accurate model development of thermodynamics and kinetics of formation, based on the discrete atom or molecule as the fundamental unit. It provides a very advanced approach down to the nanoscale level to predict their relevant molecular interactions [14-16], interlayer spacing [17-19], binding energy [17-20] and elastic properties [15]. However, this approach solely concentrates on the local molecular/atomic interactions and hierarchical structures and behaviour, which might be constrained by scaling up the integrated lengths or huge time scales to globally characterise the structures of nanocomposites. The applicability of continuum mechanics using FEA has also been faced with great attention by applying the integrated representative volume elements (RVE) with a nanometric second phase $[12,21,22]$. The general use of microstructures of composite materials by either well-aligned RVE [21, 22] or randomly distributed RVE with Monte Carlo method [12] still cannot conform to the actual complicated and highly heterogeneous nanocomposite morphology. As a result, the lack of a fine detailed structural interpretation necessitates the object-oriented finite element (OOF) analysis [23-25] to deal with a small-scaled and disordered heterogeneous material system. OOF analysis is quite a novel numerical approach to incorporate morphological images, acquired from scanning electron microscopy (SEM) or transmission electron microscopy (TEM), into 2-D finite element modelling by mapping the computational grids. The advantage of OOF technique is to combine the data in the real form of micro/nanostructures such as particle size, shape, spatial position and real orientation, 
with fundamental material parameters including elastic modulus, Poisson's ratio, coefficient of thermal expansion of constitutive phases to understand the overall material behaviour. Although OOF is temporarily limited to the calculations of elasticity and thermal conductivity in 2-D microstructures, it has given very promising results in analysing stress transfer [26], fracture mechanisms [27-29], crack propagations [30], residual thermal stresses [31, 32] and thermal conductivities [33] of heterogeneous materials. More recently, OOF modelling has also been employed in predicting the elastic moduli of nanocomposites, in reasonable agreement with experimental data and theoretical analyses of Halpin-Tsai and Lewis-Nielsen models [34-36].

The aim of present work is to introduce an image-based extended OOF modelling technique based on mapping the real micro/nanostructures of clay platelets to predict the elastic moduli of $\mathrm{PP} /$ clay nanocomposites and evaluate the deformation mechanism resulting from the clay particle distribution effect in an isotropic linear elastic condition. The results are then compared with both experimental data and conventional composites theories in order to understand the micro/nanostructure-mechanical property relationship of tailored PP/clay nanocomposites.

\section{Modelling of elastic modulus}

\subsection{Composites theoretical models}

For a conventional composite system, a series of micromechanical models [37] have been developed to handle the factorial effects of filler geometry, content and orientation, as well as the property ratio of filler and matrix on the reinforcement and mechanical properties of composites. Furthermore, the simplified geometry for each constituent and the assumption of perfect bonding interfaces, though not accurate, are widely admitted by the material manufacturers and engineers to predict the composite stiffness. 


\subsubsection{Halpin-Tsai model}

Halpin-Tsai model [8] is a well-known composites theory in the fibre composites industry to predict elastic moduli of unidirectional composites as the function of filler volume fraction and aspect ratio. In this model, filler geometries can be varied with discontinuous reinforcements such as fibre-like or flake-like fillers. The longitudinal and transverse moduli $E_{11}$ and $E_{22}$ of a composite material in Halpin-Tsai model are generally expressed as

$$
\begin{gathered}
\frac{E_{c}}{E_{m}}=\frac{1+\zeta \eta \phi_{f}}{1-\eta \phi_{f}} \\
\eta=\frac{\frac{E_{f}}{E_{m}}-1}{\frac{E_{f}}{E_{m}}+\zeta}
\end{gathered}
$$

where $E_{c}, E_{f}$ and $E_{m}$ are Young's moduli of composites, fillers and the polymer matrix, respectively. $\phi_{f}$ is the filler volume fraction and $\zeta$ is a shape parameter depending on the filler geometry and loading direction. $\zeta=2(L / d)$ for fibres or $2(L / t)$ for disk-like platelets when calculating the longitudinal elastic modulus $E_{11}$; whereas, as an approximation, $\zeta=2$ for transverse elastic modulus $E_{22}$ due to its relative insensitivity to fibre aspect ratio. $L, d$ and $t$, are the length, diameter and thickness of dispersed fillers, respectively.

\subsubsection{Hui-Shia model}

Hui-Shia model [38] is developed to predict the elastic moduli of composites including unidirectional aligned platelets with the simple assumption of perfect interfacial bonding between the polymer matrix and platelets, which is given by

Longitudinal elastic modulus $\left(E_{11}\right)$ 


$$
\frac{E_{c}}{E_{m}}=\frac{E_{11}}{E_{m}}=\frac{1}{1-\frac{\phi_{f}}{4}\left[\frac{1}{\xi}+\frac{3}{\xi+\Lambda}\right]}
$$

Transverse elastic modulus $\left(E_{22}\right)$

$$
\frac{E_{22}}{E_{m}}=\frac{1}{1-\frac{\phi_{f}}{\xi}}
$$

with

$$
\begin{gathered}
\xi=\phi_{f}+\frac{E_{m}}{E_{f}-E_{m}}+3\left(1-\phi_{f}\right)\left[\frac{(1-g) \alpha^{2}-\frac{g}{2}}{\alpha^{2}-1}\right] \text { and } g=\frac{\pi}{2} \alpha \\
\Lambda=\left(1-\phi_{f}\right)\left[\frac{3\left(\alpha^{2}+0.25\right) g-2 \alpha^{2}}{\alpha^{2}-1}\right]
\end{gathered}
$$

where $\alpha=t / L$ for disk-like platelets $(\alpha \leq 0.1)$.

\subsubsection{Laminate model}

More importantly, clay platelets in nanocomposites inevitably contain some degree of misalignment and random orientation while in the conventional composite theories, unidirectionally aligned fillers are normally assumed for simplicity. In the case of completely random orientation in all three orthogonal directions, the approximation equations for elastic moduli of fibre and platelet reinforced composites moduli $E_{\text {ran-3D }}$ based on the laminate theory $[39,40]$ are derived as

$$
\begin{gathered}
E_{\text {ran-3D }}^{\text {fibres }}=0.184 E_{/ /}+0.816 E_{\perp} \\
E_{\text {ran }-3 D}^{\text {platelets }}=0.49 E_{/ /}+0.51 E_{\perp}
\end{gathered}
$$

where $E_{/ /}$and $E_{\perp}$ are the composite moduli in the directions parallel and perpendicular to the major axis of fillers, respectively. Laminate model provides the insight to predict the elastic moduli of nanocompsites with randomly oriented clay platelets resembling the real morphological structures. 


\subsubsection{Modified rule of mixture (MROM)}

The modified rule of mixture (MROM) is initially introduced to consider the misorientation effect on the imperfectly misaligned random short fibres reinforced into thermoplastics [41, 42]. The similar semi-empirical relationship is further adopted for the flake-like fillers [38] in composite materials as

$$
E_{c}=\phi_{f} E_{f}(M R F)+\left(1-\phi_{f}\right) E_{m}
$$

where MRF stands for the Modulus Reduction Factor due to the less positive contribution of 2-D flake/platelet fillers to the unidirectional reinforcement. The Modulus Reduction Factor is proposed in two major different forms for flake-like fillers based on the Riley's rule [43] and Padawer and Beecher's rule [44], respectively:

$$
\text { Riley form of MRF: } \quad M R F=1-\frac{\ln (u+1)}{u}
$$

Padawer and Beecher form of MRF: $M R F=1-\frac{\tanh u}{u}$

with

$$
u=\frac{1}{\alpha} \sqrt{\frac{\varphi_{f} G_{\boldsymbol{m}}}{E_{f}\left(1-\varphi_{f}\right)}}
$$

where $\alpha$ is the inverse aspect ratio of dispersed fillers and $G_{m}$ is the shear modulus of the polymer matrix. MRF might lie in the range between 0.167 and 1 for randomly disposed short fibres [41]. In a special case of platelet fillers, $\mathrm{MRF}=0.66$ [45] has been shown to well predict the tensile moduli of rubber/clay nanocomposites over a wide range of clay volume fractions.

\subsection{Real morphological image-based numerical simulation}

\subsubsection{Initial setup}

The addition of a small amount of clay particles as rigid nanofillers can significantly enhance the mechanical properties of PP/clay nanocomposites, especially the elastic moduli. 2-D computational models have been established using an object-oriented finite element (OOF) code, 
OOF 2.0.4 [24], developed by the National Institute of Standards and Technology (NIST), USA, to predict their elastic moduli at various clay contents ranging from 3, 5, 8 to $10 \mathrm{wt} \%$. OOF 2.0.4 package, installed in a Fedora Red Hat Core 4 Linux system, comprises a preprocessor interface to correlate the real morphological images to the micro/nanostructures, generate the mesh grids with assigned material properties and apply the loading and boundary conditions to the domain, as well as the solver with a postprocessor OOF for the contour illustration of stress/strain state in each element. The finite element analysis was conducted on a Dell INSPIRONTM 8600 laptop with the Windows XP and Linux dual boot system using 1.6 GHz processors and 2 GB RAM.

Initially, a representative region of interest in Fig. 1(a) was selected from a typical TEM micrograph of $5 \mathrm{wt} \%$ filled $\mathrm{PP} /$ clay nanocomposites. Then the image segmentation using the pixel selection tool was employed to assign the material properties to clay particles and the PP matrix, Fig. 1(b). The 2-D finite element mesh was subsequently created based on OOF skeleton to display all the details of micro/nanostructures of clay platelets with the actual size and shape, orientation and spatial position. The mesh generation began with the conformity of right triangular or quadrilateral elements over micro/nanostructures and then was followed by the mesh refinement process using an energy functional minimisation approach [25] so that sufficient refined elements could be situated around the critical matrix-particle interfaces where higher stress gradients occurred, Fig. 1(c). This scheme does not significantly increase the total number of elements due to the element subdivisions arising mainly in the interfaces, thus reducing computational time during the simulation.

\subsubsection{Fundamental assumptions of 2-D analysis}

Both clay particles and the PP matrix were reasonably hypothesised to be isotropic linear elastic materials since the elastic properties of nanocomposites are accentuated. To further simplify 
the matrix-reinforcement adhesion, a perfect interfacial bonding was assumed between two constituents. In fact, the interfacial adhesion could be greatly improved by utilising the compatibilisers such as maleated PP. On the other hand, conventional 2-D numerical simulation might also neglect the effect of thickness dimension provided that the other two dimensions presented in a 2-D domain are significantly large. Furthermore, constructed OOF models undergo a virtual simulation of uniaixal tensile test with an in-plane stretching mode. Hence the resulting tensile stresses were calculated based on OOF models with the unit thickness subjected to a plane stress condition for the estimation of elastic modulus.

The material properties of the constituents used for this study are listed in Table 1, which consider only the simple case of "ideally isotropic homogenised particles" $[7,10,12,46]$ for the intercalated clay platelets to calculate the clay elastic modulus and Poisson's ratio. In a real case, both aligned and skewed clay particles exist with a mix of intercalated/exfoliated structures though intercalation is more prevalent in PP/clay nanocomposites. Nonetheless, the calculation of actual Young's modulus of clay particles appears to be very tedious if the clay dispersion level must be quantitatively identified in good precision and thus is beyond the scope of this work.

To define the boundary conditions, as depicted in Fig. 1(c), both $x$ and $y$ displacements $U_{x}, U_{y}$ on the left vertical edge of domain were set to zero (i.e. fully constrained) and constant horizontal displacement $U_{x}$ on the right vertical edge was applied which was equivalent to $0.05 \%$ and $0.25 \%$ elastic strains in the actual tensile tests, respectively.

\subsubsection{Prediction of effective in-plane elastic modulus}

The effective in-plane elastic modulus of nanocomposites was predicted from the computed nodal reactions caused by the in-plane stretching of OOF models, namely the sum of the boundary forces acting on the right vertical edge of OOF models. The relevant formula is expressed as 


$$
E_{\text {eff }}=\frac{L_{x} \sum_{i=1}^{n} F_{i}}{L_{y} \Delta L}
$$

where $F_{i}$ is the reaction on the $i$ th node in the $x$ direction. $n$ is a set number of boundary nodes under the nonzero displacement condition. $\Delta L$ is the prescribed in-plane displacement and $L_{x}, L_{y}$ are the horizontal and vertical dimensions of OOF modelling domain.

\subsubsection{Limitation of 2-D numerical work}

Not withstanding that OOF modelling is a very feasible computational approach, it is constrained to a linear elastic deformation of materials based on 2-D microscopic images. When considering more accurate 3-D visualisation, the X-ray nanotomography technique [47] by using Nano-CT scanner $[48,49]$ in the resolutions of just a few hundred nanometers, along with the data acquisition interfaces such as Mimics ${ }^{\circledR}$ [50] or in-housing developed Octopus [51], might necessitate the volumetric reconstructions of actual 3-D nanocomposite morphological structures. Such sophisticated 3-D virtual model geometry could be eventually incorporated into the commercial finite element codes like ABAQUS $®$ or ANSYS $®$, thus extending the computational capacity to predict the entire elastic-plastic material behaviour of nanocomposites. However, the fine detailed volumetric reconstruction could be very time-consuming due to different ranges of embedded nanoparticles in skewed or well-aligned formations with the micro/nanoscaling effect. Besides, for simplicity, it is also out of the scope of current study when the prediction of elastic modulus is of great concern.

\section{Results and Discussion}

\subsection{Effect of clay orientation state on elastic modulus}

Since the orientation of clay particles has a very significant influence on the elastic modulus apart from their aspect ratio and shape parameter $[10,52]$, OOF modelling results are compared 
with the experimental data [46], typical Halpin-Tsai and Hui-Shia models with both unidirectional platelet alignment and 3-D random platelet orientation, as well as the modified rule of mixture (MROM), Fig. 2. Apparently, the modelling results well capture the linear increasing trend of elastic modulus with increasing the clay content, in good accordance with the experimental data though prone to the slight overestimation. Such discrepancy can be associated with neglecting the compatibiliser and interphase properties, as well as the artefacts and phase distinction problem in the imaging analysis. Moreover, it also lies in the simple assumption of perfect bonding condition at the interfaces, which might not be the case for PP/clay nanocomposites since polyolefin-based nanocomposites really lack this strong adhesion with only weak van der Waals forces existing in the clay interlayers [53].

On the other hand, due to the presence of prevalent stacks of intercalated platelets within the PP matrix, the experimental data have also fitted composites theoretical models at various clay aspect ratios $(L / t=5 \sim 80)$. It is worth noting that the unidirectional alignment state is derived from the theoretical calculations of unmodified Halpin-Tsai and Hui-Shia models in Eqs. (1) and (3), respectively, while 3-D random orientation state is based on Halpin-Tsai laminate hybrid and Hui-Shia laminate hybrid models obtained from Eqs. (1), (3), (4) and (8). At a fixed aspect ratio, each curve for the random orientation, clearly seen in Figs. 2(b) and (d), lies below the corresponding one for the unidirectional alignment in Figs. 2(a) and (c). This is attributed to the practical standpoint in conventional composites theory that any deviation from unidirectional reinforcements inevitably leads to a sizeable reduction in composite stiffness, the extent of which depends on the filler shape [10]. Such modulus reduction phenomenon due to the different filler orientation states becomes more pronounced in Halpin-Tsai laminate hybrid model compared to the unmodified Halpin-Tsai model that mainly deals with discontinuous fibre-like fillers, Figs. 2(a) and 
(b). Nevertheless, Hui-Shia laminate hybrid model demonstrates less modulus reduction as compared to unmodified Hui-Shia model for the disk-like platelet filler geometry with the biaxial reinforcement, Fig. 2(c) and (d). It is quite evident that platelets appear not to be as sensitive as fibres to the orientation states, which can be beneficial to a nanocomposite system that requires an effective multi-directional reinforcement. Furthermore, despite the consideration of Modulus Reduction Factor (MRF) in modified rule of mixture (MROM), two different forms of MROM start to deviate greatly from one another, Figs. 2(e) and (f). Beyond the aspect ratio of 10 as the threshold for intercalation [13], consistently higher elastic moduli are revealed for Padawer and Beecher form relative to Riley form. The MROM with $\mathrm{MRF}=0.66$ clearly presents the overprediction to the experimental data and the extent of variation becomes more worth noting at the higher clay content $(8-10 \mathrm{wt} \%)$

The curve-fitting aspect ratios as the good indicator of reinforcement efficiency in PP/clay nanocomposites are also listed in Table 2. The experimental data with a low clay content (below 5 $\mathrm{wt} \%$ ) lie within all the theoretical models at relatively large aspect ratios compared to those with a high content level $(8-10 \mathrm{wt} \%)$. This is due to the fact that with increasing the clay content, the number of clay particles is also increased, inevitably resulting in smaller aspect ratios with a possibility of forming clay tactoids. In order to achieve the same modulus at a given clay content, higher aspect ratios are required in Halpin-Tsai laminate hybrid and Hui-Shia laminate hybrid models to compensate for the modulus reduction due to the 3-D filler random orientation. For instance, at the clay content of $3 \mathrm{wt} \%$, the aspect ratios fitting these two models for such nanocomposites are observed to be around 40 in contrast to 10 in Halpin-Tsai model and 20-40 in Hui-Shia model. More interestingly, Halpin-Tsai laminate hybrid model and unmodified Hui-Shia model show very similar curve-fitting aspect ratios beyond the clay content of $3 \mathrm{wt} \%$, which might arise from the fibre-like 
filler random orientation, thus enhancing the possibility of biaxial reinforcement effect. The consistent agreement of aspect ratios is also found at the given clay content when fitted by MROM in both Riley form and Padawer and Beecher form. Nonetheless, each of the composites theoretical models fails to predict the experimentally determined elastic moduli accurately with any fixed aspect ratio, which indicates the limitation of these semi-empirical relationships with the ideal assumptions of identical filler geometry, constant aspect ratio and lack of interfacial slip, filler-polymer debonding or matrix cracking, etc. On the contrary, the morphological structures of PP/clay nanocomposites appear to be more complicated with a mix of intercalated, exfoliated clay platelets and aggregated tactoids. Such imperfection inevitably leads to different levels of discrepancy from the theoretical models.

\subsection{Effect of clay particle dispersion on stress transfer and deformation mechanism}

The effect of clay dispersion for PP/clay nanocomposites has also been investigated from the uniaxial stress contours $\left(\sigma_{x x}\right)$ subjected to $0.25 \%$ elastic strain, Fig. 3. As expected, the tensile stresses become much lower in the PP matrix region free of clay particles while the higher stresses are often visible around the interfacial area between clay particles and the PP matrix. It is implied that the interface in nanocomposites plays an important role in the effective load transfer from the matrix to the fillers. Furthermore, increasing the clay content from 3 to $10 \mathrm{wt} \%$ can also lead to the stress enhancement on the PP matrix owing to the more frequent particle-to-particle contact when the number of clay particles increases (i.e. decreasing the interparticle spacing). The stress intensification phenomenon becomes manifested at the sharp edges of clay particles, acting as the stress concentration sites, especially where the clay platelets are tailored to be well-aligned with the loading direction. Similarly, the localised high stress concentration has also been found in the regions with an increasing number of clay particles to contact, which expectedly appears to be more 
pronounced at a higher clay content (8-10 wt\%), Figs. 3(c) and (d). The orientation state of clay particles, on the other hand, can also substantially influence the local stresses in a unidirectional tensile mode. As illustrated in region A, Fig. 3(a), clay particles with a more favourable alignment along the loading direction undergo higher stresses compared to the particles that are almost perpendicular to the applied load in region B. This finding further supports the key point in the general composite theories that the variations in composites strengths and moduli along the longitudinal and transverse directions are due to the preferential orientation of the fillers. Hence, a good alignment of clay particles associated with high aspect ratios within the PP matrix is quite vital for the effective stress transfer in a nanocomposite system. However, such mechanism is diminished in practice owing to the real morphology of nanocomposites where various degrees of the random orientation of clay particles exist. The localised high stress field around clay particles obviously induces the possibility of nanocomposite failure and damage, especially at a higher clay content, resulting from the clay particle clustering and contact increment.

The corresponding elastic strain contours $\left(\varepsilon_{x x}\right)$ for the local deformation behaviour are depicted in Fig. 4. Since rigid fillers like clay particles can naturally resist the deformation (i.e. straining) due to their high modulus, the elastic strains of all clay particles become relatively small compared to those of the PP matrix regardless of the clay content in such nanocomposites. PP matrix regions full of clay particles indicate the higher strains parallel to the loading direction. Apart from the clay intercalated structures, large particle size and close particle contact promote a greater deformation level within the PP matrix in the vicinity of clay particles, where the weak zones are developed leading to mechanical failures. Conversely, the particle-free PP matrix becomes less deformed and more inhomogeneous elastic strain distributions are clearly observed with increasing the clay content. In this study, OOF modelling results clearly show that the reason for poor mechanical 
properties is often associated with the particle agglomeration for nanocomposites with higher clay contents. They also highlight the importance of properly processing nanocomposites and getting a better clay particle distribution.

\section{Conclusions}

The novel OOF modelling technique provides the great insight to well predict the elastic moduli of PP/clay nanocomposites in comparison to conventional composites theories. It also creates an opportunity to investigate the deformation mechanism of clay particles on the basis of mapping the real micro/nanostructures. As expected, the orientation of clay particles has been shown to make a great impact on the elastic moduli of PP/clay nanocomposites. Besides, the modulus reduction is revealed to be more significant in Halpin-Tsai laminate hybrid model and MROM with Riley form $(L / t>10)$ when compared to corresponding unmodified Halpin-Tsai model for the fibre-like filler geometry and MROM with Padawer and Beecher form $(L / t>10)$, respectively. Its influence due to different orientation states becomes less severe when Hui-Shia laminate hybrid model and unmodified Hui-Shia model are considered, mainly benefiting from the biaxial reinforcement in platelet filler geometry. The study of particle distribution establishes beyond doubt that the uniform clay dispersion is still a key issue from both experimental and numerical point of view as clay clusters can lead to the localised stress concentrations, thus making nanocomposites more prone to failures. As such the manufacturing methodology of the nanocomposites assumes a very important role for producing the structural integrity of the end products.

\section{Acknowledgements}

Financial support for this study was provided by the Tertiary Education Commission (TEC), New Zealand and the Foundation for Research, Science and Technology (FRST), New Zealand 
under FRST grant \#UOAX 0406. The authors also gratefully acknowledge Drs. Seung-Ill Haan and

Stephen A. Langer (NIST, USA) for their kind technical assistance in OOF modelling.

\section{References}

[1] Lei SG. Formulation and mechanical properties of polypropylene nanocomposites. M.ASc thesis, Concordia University, Department of Mechanical and Industrial Engineering, 2003.

[2] Lertwimolnun W, Vergnes B. Polymer 2005; 46: 3462-71.

[3] Hasegawa N, Kawasumi M, Kato M, Usuki A, Okada A. J Appl Polym Sci 1998; 67: 87-92.

[4] Liu XH, Wu QJ. Polymer 2001; 42:10013-9.

[5] Wang Y, Cheng FB, Wu KC. J Appl Polym Sci 2004; 93:100-12.

[6] Perrin-Sarazin F, Ton-That MT, Bureau MN, Denault J. Polymer 2005; 46:11624-34.

[7] Kim DH, Fasulo PD, Rodgers WR, Paul DR. Polymer 2007; 48:5308-23.

[8] Halpin JC, Kardos JL. Polym Eng Sci 1976; 16:344-52.

[9] Mori T, Tanaka K. Acta Metall 1973; 21:571-4.

[10] Fornes TD, Paul DR. Polymer 2003; 44:4993-5013.

[11] Brune DA, Bicerano J. Polymer 2002; 43:369-87.

[12] Sheng N, Boyce MC, Parks DM, Rutledge GC, Abes JI, Cohen RE. Polymer 2004; 45:487-506.

[13] Luo JJ, Daniel IM. Compos Sci Technol 2003; 63:1607-16.

[14] Hackett E, Manias E, Giannelis EP. Chem Mater 2000; 12:2161-7.

[15] Odegard GM, Clancy TC, Gates TS. Polymer 2005; 46:553-62.

[16] Katti KS, Sikdar D, Katti DR, Ghosh P, Verma D. Polymer 2006; 47:403-14.

[17] Fermeglia M, Pricl S. Prog Org Coat 2007; 58:187-99.

[18] Toth R, Coslanich A, Ferrone M, Fermeglia M, Pricl S, Miertus S, Chiellini E. Polymer 2004; 45:8075-83.

[19] Fermeglia M, Ferrone M, Pricl S. Mol Simul 2004; 30:289-300.

[20] Toth R, Ferrone M, Miertus S, Chiellini E, Fermeglia M, Pricl S. Biomacromolecules 2006; $7: 1714-9$.

[21] Zhu LJ, Narh KA. J Polym Sci Part B 2004; 42:2391-406.

[22] Fertig III RS, Garnich MR. Compos Sci Technol 2004; 64:2577-88. 
[23] Langer SA, Fuller Jr ER, Carter WC. Comput Sci Eng 2001; 3:15-23.

[24] Langer SA, Reid ACE, Haan SI, Garcia RE. The OOF2 manual: Revision 3.7 for OOF2 Version 2.0.4, the National Institute of Standards and Technology (NIST), USA.

[Online]: http://www.ctcms.nist.gov/ langer/oof2man/index.html

[25] Chawla N, Patel BV, Koopman M, Chawla KK, Saha R, Patterson BR, Fuller ER, Langer SA. Mater Charact 2003; 49:395-407.

[26] Hsueh CH, Fuller Jr ER, Langer SA, Carter WC. Mater Sci Eng A 1999; 268:1-7.

[27] Zimmermann MH, Baskin DM, Faber KT, Fuller Jr ER, Allen AJ, Keane DT. Acta Mater $2001 ; 49: 3231-42$.

[28] Cannillo V, Pellacani GC, Leonelli C, Boccaccini AR. Compos. Part A 2003; 34:43-51.

[29] Cannilo V, Leonelli C, Manfredini T, Montorsi M, Veronesi P, Minay EJ, Boccaccini AR. Compos Sci Technol 2005; 65:1276-83.

[30] Cannillo V, Manfredini T, Montorsi M, Siligardi C, Sola A. J Eur Ceram Soc 2006; 26:3067-73.

[31] Vedula VR, Glass SJ, Saylor DM, Rohrer GS, Carter WC, Langer SA, Fuller ER. J Am Ceram Soc 2001; 84:2947-54.

[32] Cannillo V, Leonelli C and Boccaccini AR. Mater Sci Eng A 2002; 323:246-50.

[33] Wang Z, Kulkarni A, Deshpande S, Nakamura T, Herman H. Acta Mater 2003; 51:5319-34.

[34] Cannillo V, Bondioli F, Lusvarghi L, Montorsi M, Avella M, Errico ME, Malinconico M. Compos Sci Technol 2006; 66:1030-7.

[35] Avella M, Bondioli F, Cannillo V, Errico ME, Ferrari AM, Focher B, Malinconico M, Manfredini T, Montorsi M. Mater Sci Technol 2004; 20:1340-4.

[36] Bondioli F, Cannillo V, Fabbri E, Messori M. J Appli Polym Sci 2005; 97:2382-6.

[37] Tucker III CL, Liang E. Compos Sci Technol 1999; 59:655-71.

[38] Hui CY, Shia D. Polym Eng Sci 1998; 38:774-82.

[39] van Es M, Xiqiao F, van Turnhout J, van der Giessen E. In: Al-Malaika S, Golovoy AW, editors. Comparing polymer-clay nanocomposites with conventional composites using composite modelling. Specialty polymer additives: principles and applications. Chapter 21, Oxford: Blackwell Science, 2001. pp. 391-414.

[40] Hull D, Clyne TW. An introduction to composite materials. $2^{\text {nd }}$ ed., New York: Cambridge University Press, 1996. 
[41] Bowyer WH, Bader MG. J Mater Sci 1972; 7:1315-21.

[42] Curtis PT, Bader MG, Bailey JE. J Mater Sci 1978; 13:377-90.

[43]Riley VR. Interaction effects in polymer composites. Polymer conference series, University of Utah, Salt Lake City, 1970.

[44]Padawer GE, Beecher N. Polym Eng Sci 1970; 10:185-92.

[45] Wu YP, Jia QX, Yu DS, Zhang LQ. Polym Test 2004; 23:903-9.

[46] Dong Y. Multi-scale effects on deformation mechanisms of polymer nanocomposites: experimental characterisation and numerical study. $\mathrm{PhD}$ thesis, the University of Auckland, Department of Mechanical Engineering, 2008.

[47] Midgley PA, Ward EPW, Hungria AB, Thomas JM. Chem Soc Rev 2007; 36:1477-94.

[48] Hanke R, Fuchs T, Uhlmann N. Nucl Instrum Methods Phys Res A 2008; 591:14-8.

[49] Dierick M, Hoorebeke LV, Jacobs P, Masschaele B, Vlassenbroeck J, Cnudde V, Witte YD. Nucl Instrum Methods Phys Res A 2008; 591:255-9.

[50] Sun W, Starly B, Nam J, Darling A. Comput-Aided Des 2005; 37:1097-1114.

[51] Vlassenbroeck J, Dierick M, Masschaele B, Cnudde V, Hoorebeke LV, Jacobs P. Nucl Instrum Methods Phys Res A 2007; 580:442-5.

[52] Li X, Gao H, Scrivens WA, Fei D, Thakur V, Sutton MA, Reynolds AP, Myrick ML. Nanotechnology 2005; 16:2020-9.

[53] Mittal V. J Thermoplast Compos Mater 2007; 20:575-99. 


\section{List of Figures}

Fig. 1 OOF modelling procedure based on $5 \mathrm{wt} \%$ filled PP/clay nanocomposites: (a) original representative region of interest from a TEM image, (b) pixel selection in the image segmentation and (c) finite element mesh.

Fig. 2 Comparisons of experimental data, OOF modelling (TEM) results and composites theoretical models for PP/clay nanocomposites including (a) Halpin-Tsai model, (b) Halpin-Tsai laminate hybrid model, (c) Hui-Shia model, (d) Hui-Shia laminate hybrid model, (e) modified rule of mixture (MROM) with Riley form of MRF and $M R F=0.66$ and (f) modified rule of mixture (MROM) with Padawer and Beecher form of MRF and $\mathrm{MRF}=0.66$.

Fig. 3 Uniaxial stress $\left(\sigma_{x x}\right)$ contours of $\mathrm{PP} /$ clay nanocomposites with various clay contents ( $U_{x}=0.25 \%$ strain): (a) $3 \mathrm{wt} \%$, (b) $5 \mathrm{wt} \%$, (c) $8 \mathrm{wt} \%$ and (d) $10 \mathrm{wt} \%$.

Fig. 4 Elastic strain $\left(\varepsilon_{x x}\right)$ contours of PP/clay nanocomposites with various clay contents ( $U_{x}=0.25 \%$ strain): (a) $3 \mathrm{wt} \%$, (b) $5 \mathrm{wt} \%$, (c) $8 \mathrm{wt} \%$ and (d) $10 \mathrm{wt} \%$. 


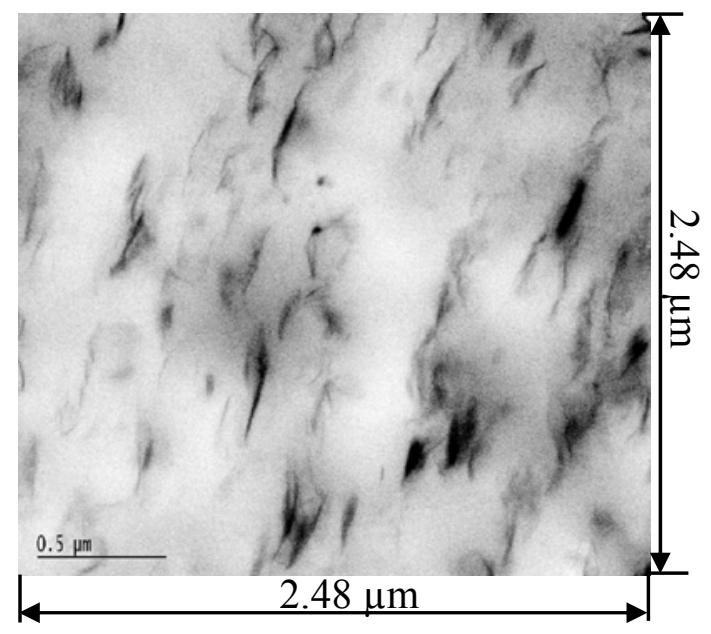

(a)

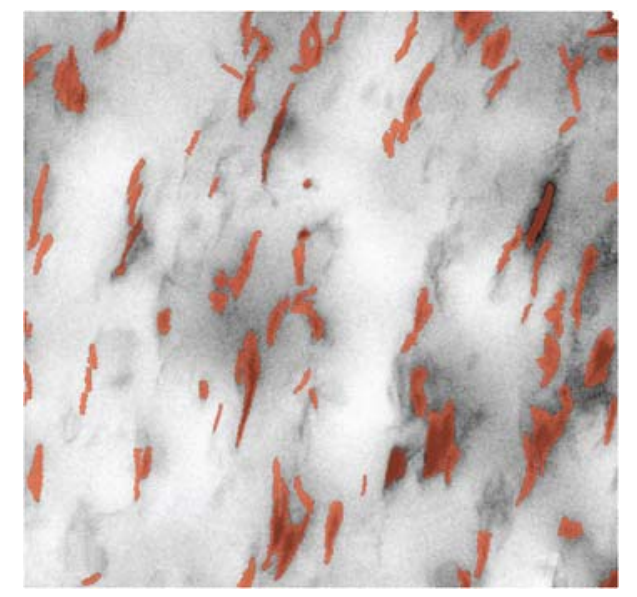

(b)

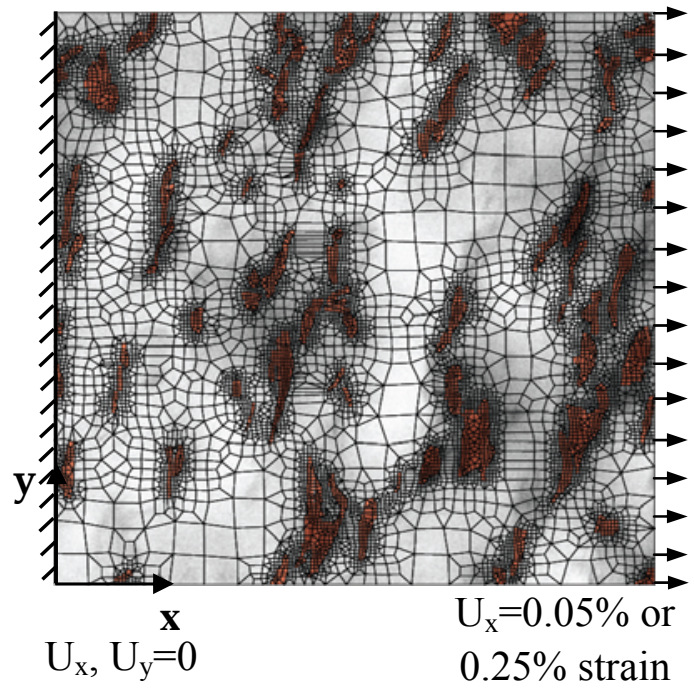

(c)

Fig. 1 

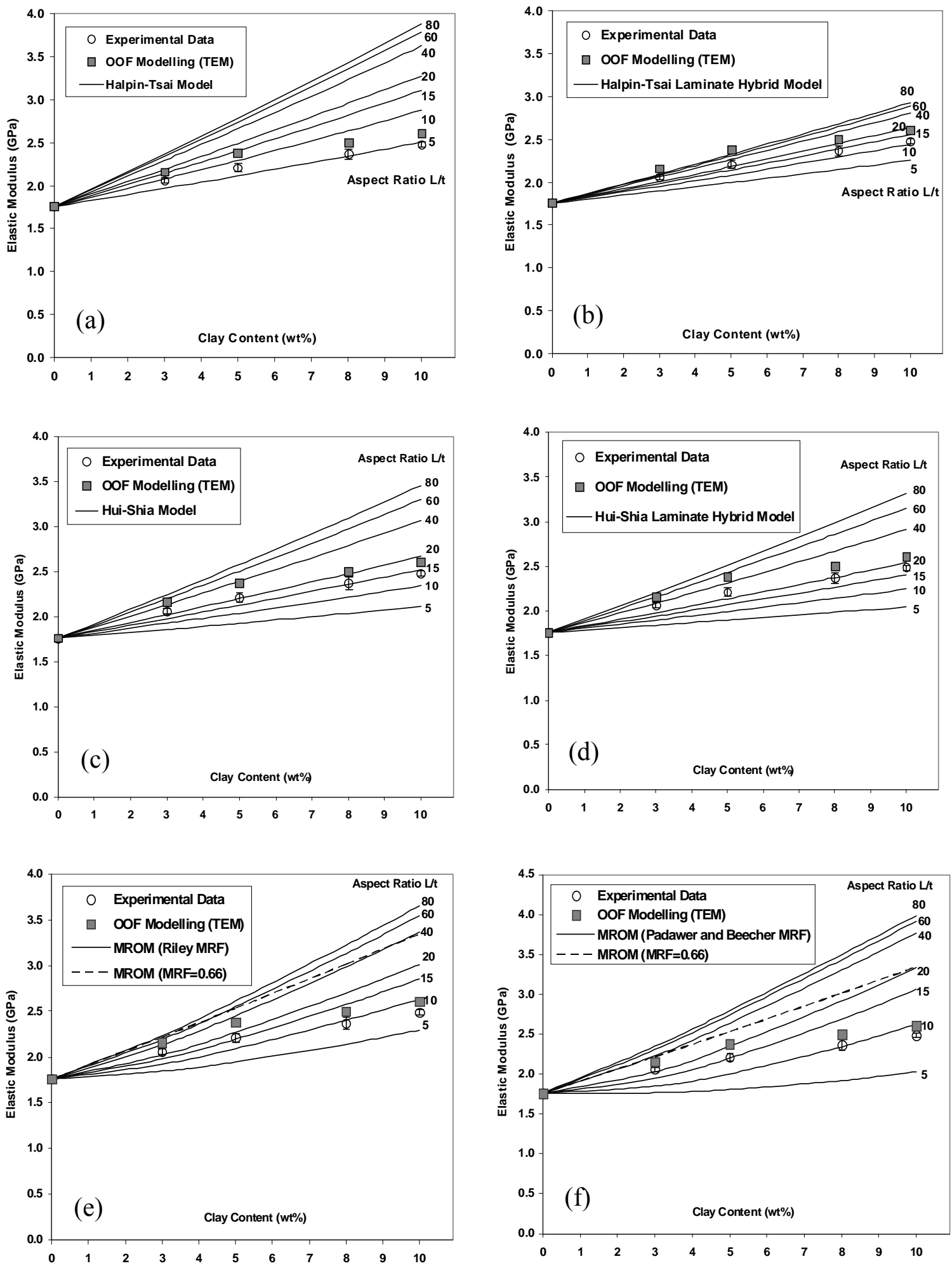

Fig. 2 


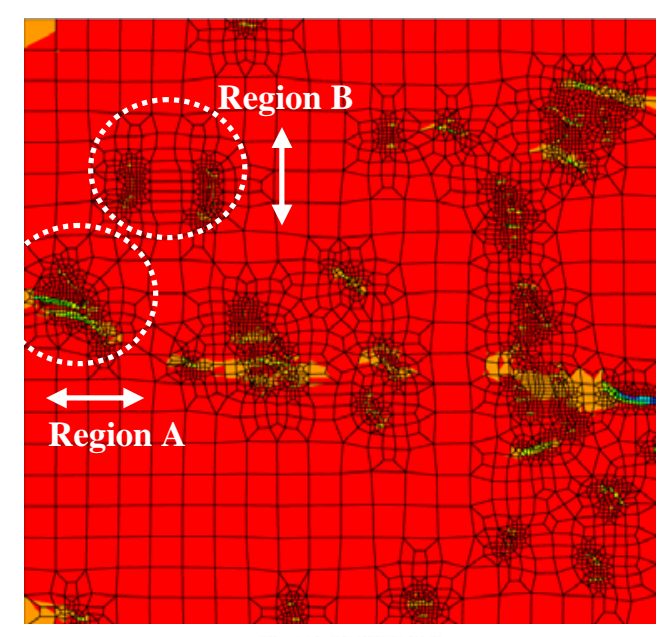

$\sigma_{\mathrm{ux}} \times 10^{-3}(\mathrm{GPa})$

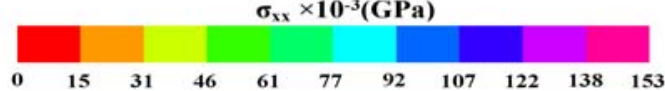

(a)

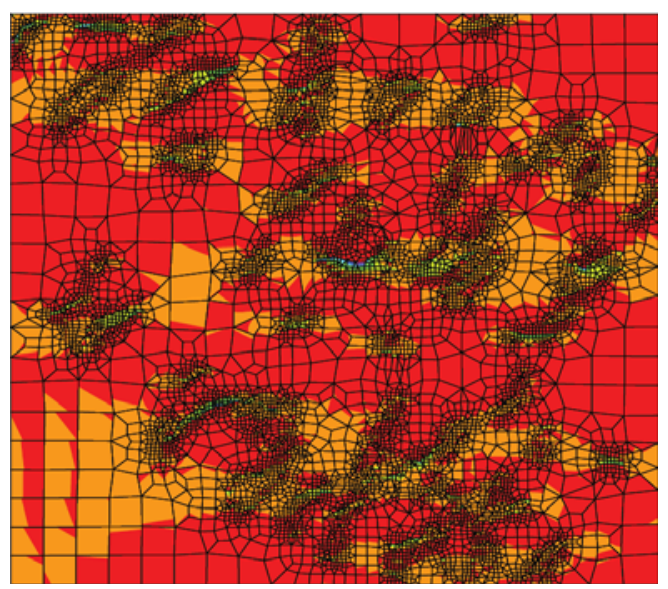

$\sigma_{\mathrm{xx}} \times 10^{-3}(\mathrm{GPa})$

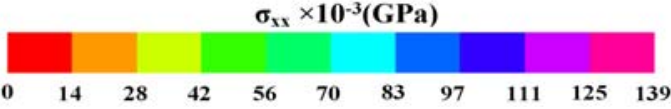

(c)

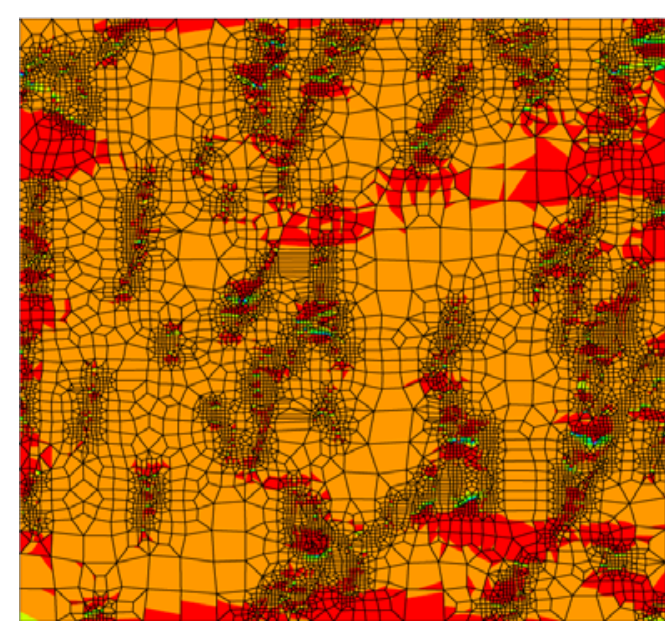

$\sigma_{\mathrm{xx}} \times 10^{-3}(\mathrm{GPa})$

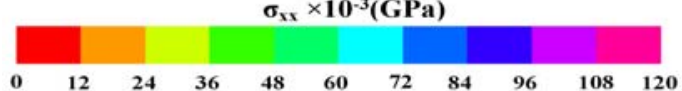

(b)

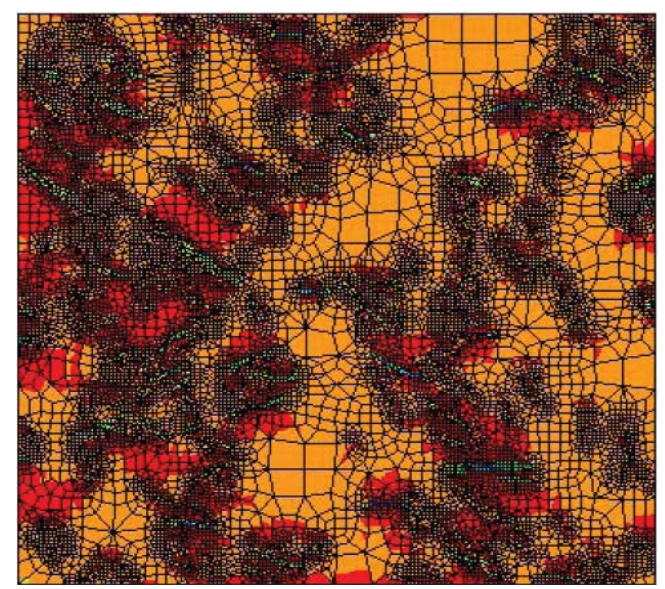

$\sigma_{\mathrm{xx}} \times 10^{-3}(\mathrm{GPa})$

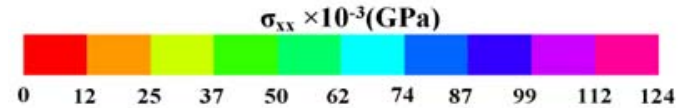

(d)

Fig. 3 


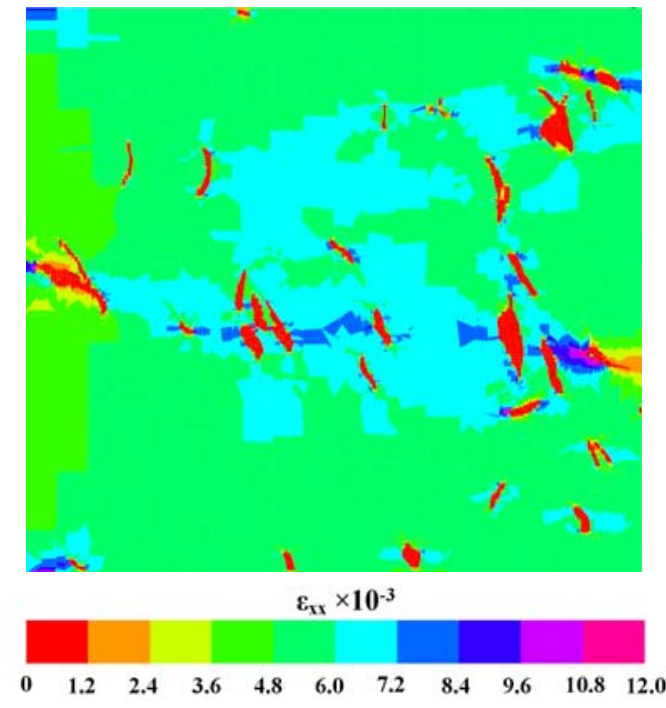

(a)

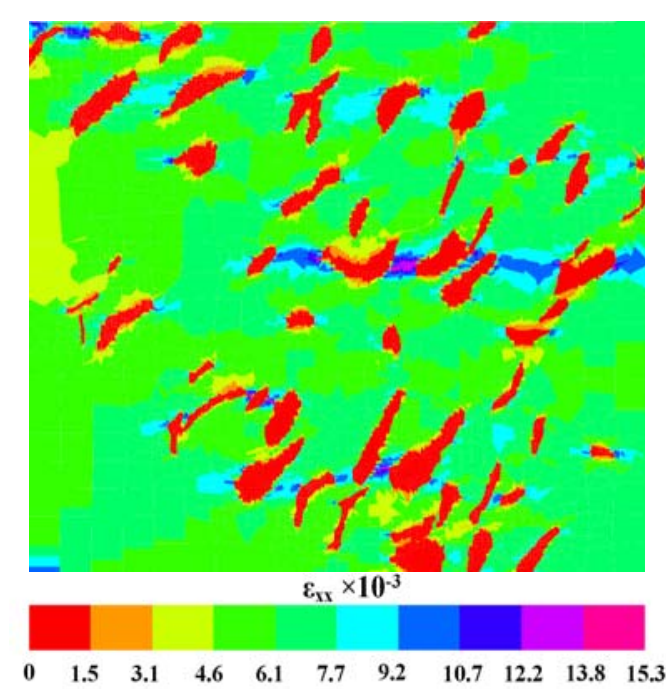

(c)

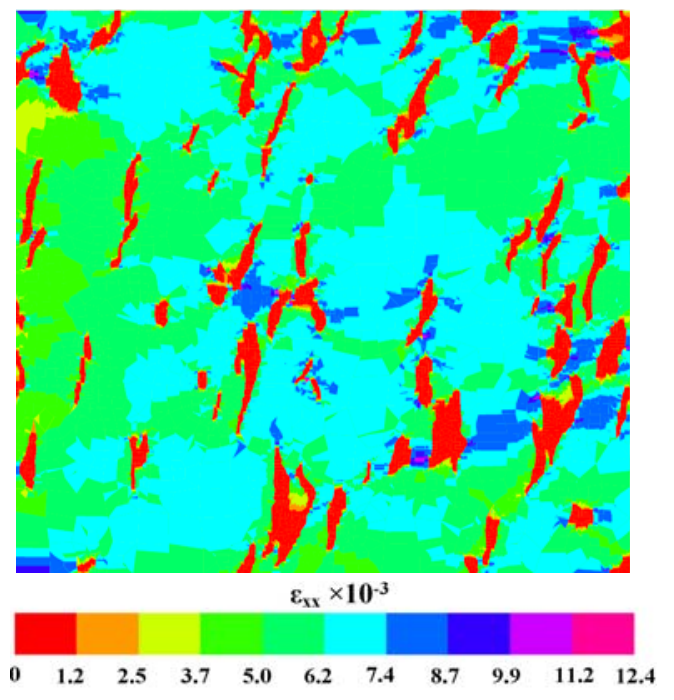

(b)

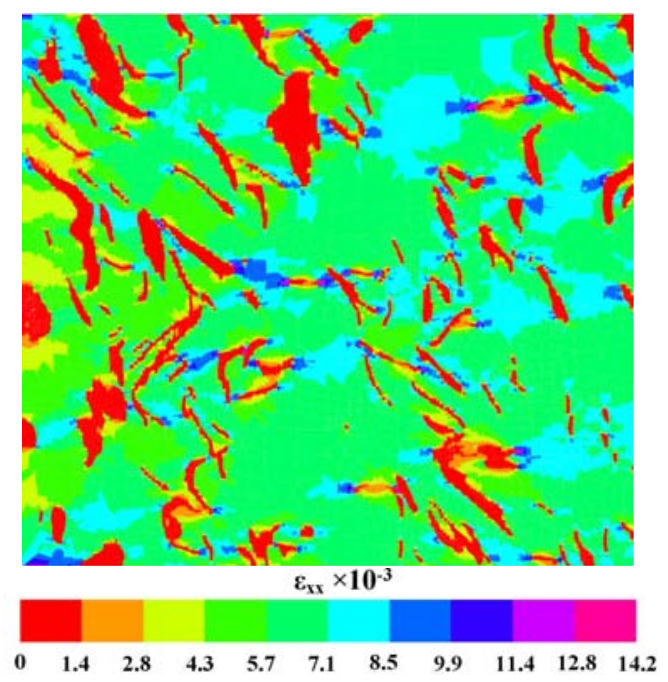

(d)

Fig. 4 
Table 1 Constituent properties of PP/clay nanocomposites

\begin{tabular}{cccc}
\hline & PP matrix & Clay particles & References \\
\hline Young's modulus (GPa) & $1.76^{\mathrm{a}}$ & $48.3^{\mathrm{b}}$ & $\begin{array}{c}{ }^{\mathrm{a}} \text { Experimental data [46] } \\
\text { balculated on average based on } \\
\text { measured clay interlayer spacing } \\
d_{001} \text { from [46] }\end{array}$ \\
Poisson's ratio & $0.35^{\mathrm{c}}$ & $0.26^{\mathrm{d}}$ & ${ }^{\mathrm{c}}[10]$ and ${ }^{\mathrm{d}}[7]$ \\
Density $\left(\mathrm{g} / \mathrm{cm}^{3}\right)$ & 0.9 & 1.8 & Material data sheet \\
\hline
\end{tabular}

Table 2 Curve-fitting aspect ratios between experimental data and composites theoretical models for PP/clay nanocomposites

\begin{tabular}{ccccccc}
\hline \multirow{2}{*}{$\begin{array}{c}\text { Clay } \\
\text { content } \\
(\mathrm{wt} \%)\end{array}$} & $\begin{array}{c}\text { Halpin-Tsai } \\
\text { model }\end{array}$ & $\begin{array}{c}\text { Halpin-Tsai } \\
\text { laminate } \\
\text { hybrid model }\end{array}$ & $\begin{array}{c}\text { Hui-Shia } \\
\text { model }\end{array}$ & $\begin{array}{c}\text { Hui-Shia } \\
\text { laminate } \\
\text { hybrid model }\end{array}$ & $\begin{array}{c}\text { MROM } \\
\text { (Riley MRF) }\end{array}$ & $\begin{array}{c}\text { MROM } \\
\text { (Padawer and } \\
\text { Beecher MRF) }\end{array}$ \\
\hline 3 & 10 & 40 & $20-40$ & $\sim 40$ & $20-40$ & $20-40$ \\
5 & $5-10$ & $\sim 20$ & $\sim 20$ & $20-40$ & $\sim 15$ & $\sim 15$ \\
8 & $\sim 5$ & $\sim 15$ & $\sim 15$ & 20 & $\sim 10$ & $\sim 10$ \\
10 & $<5$ & $10-15$ & $10-15$ & $15-20$ & $5-10$ & $5-10$ \\
\hline
\end{tabular}

